\title{
AS OBRAS E OS DIAS, DE HESÍODO, POR JOÃO FÉLIX PEREIRA
}

\author{
Alessandro Rolim de Moura ${ }^{\star}$ \\ Universidade Federal do Paraná
}

\begin{abstract}
This article republishes and briefly discusses the work of João Félix Pereira on Hesiod: the Portuguese translation of passages from the Works \& Days with introduction and Greek text (Lisbon, 1876).
\end{abstract}

KEYWORDS: Hesiod; João Félix Pereira; translation; textual variants.

om o recente aumento do interesse pelo poema Os trabalhos e os dias, de Hesíodo, no mundo lusófono, interesse que se pode constatar pelo bom número de traduções para o português nos últimos dez anos, ${ }^{1}$ estamos num momento propício para recuperar a memória do trabalho de João Félix Pereira, autor da primeira tradução do texto para a nossa língua. Meu trabalho aqui consiste na reedição de todo o material publicado por Pereira em seu opúsculo de 1876 (tradução, texto grego e prefácio).

Pereira, ${ }^{2}$ nascido em Lisboa em 1822 e falecido na mesma cidade em 1891, foi um prolífico escritor, tradutor e ensaísta. Estudou Letras, Medicina, Engenharia Civil, Agronomia e Comércio, tendo atuado no magistério por muitos anos e se dedicado à divulgação de vários campos

\footnotetext{
* alessandro.rolimdemoura@ufpr.br

${ }^{1}$ Pinheiro e Ferreira, 2005; Mantovaneli, 2011; Rolim de Moura, 2012; Werner, 2013.

${ }^{2}$ Para algumas indicações sobre a biografia e a obra de Pereira, ver Pereira, 1888, p. i-xxxii; Encyclopedia e diccionario internacional (vol. XV, p. 8693, s.v. Pereira, João Felix); Grande enciclopédia portuguesa e brasileira (vol. XXI, p. 148-9, s.v. Pereira, João Félix).
} 
do saber. Sua enorme obra (preservada em grande parte na coleção que leva seu nome na Biblioteca Nacional de Portugal) ${ }^{3}$ inclui, por exemplo, traduções da Ciropedia de Xenofonte e do Pro Archia de Cícero, ${ }^{4}$ de textos de outros clássicos, como Heródoto, Homero, Píndaro, Tito Lívio e Virgílio, além de versões de obras escritas em diversas línguas modernas, como o russo, o alemão e o italiano. Publicou livros e artigos em diversas áreas, incluindo Botânica, Geografia, Filologia e História (como o Resumo da história de Portugal, publicado também em inglês em 1854 como Abridgement of the history of Portugal). ${ }^{5}$

Sua tradução do poema de Hesíodo, que ele intitula As obras e os dias, não contém o poema inteiro, mas apenas aqueles versos que o autor julga terem relação mais direta com a Agricultura (somente 182 versos). Embora isso seja frustrante para qualquer amante da poesia que queira conhecer a obra de Hesíodo, em função da imagem fragmentária que essa seleção impõe, Pereira traduz utilizando versos metrificados, os "hendecassílabos" mencionados no subtítulo. Pereira utiliza, portanto, a terminologia vigente até sua época, que assim chamava o que hoje seria descrito por muitos como um verso decassílabo grave ou paroxítono, isto é, aquele em que, após a décima sílaba, que é acentuada, vem uma sílaba átona. Excepcionalmente, vêm duas átonas (caso em que o verso seria um "esdrúxulo"), o que ocorre na tradução de Pereira apenas quatro vezes, duas quando a segunda sílaba átona no final é um pronome em ênclise — em "empresta-me" e "recusando-se" — e duas outras em versos terminados por proparoxítonas — em "diâmetro", "côvados". ${ }^{6}$ Tal verso é evidentemente mais curto do que o hexâmetro datílico grego, sendo esse um dos fatores que levam Pereira a utilizar mais linhas na sua tradução do que o original grego. Os números colocados por Pereira na margem da tradução, assim, não correspondem a uma contagem exata, mas servem apenas para auxiliar o leitor na identificação das correspondências entre o texto grego e o português.

\footnotetext{
${ }^{3}$ Trata-se da Colecção PEREIRA, João Félix. Biblioteca Nacional de Portugal, $<$ http://acpc.bn.pt/colecoes_autores/n32_pereira_joao_felix.html > (último acesso em 02/ 05/ 2014).

${ }^{4}$ A obra sobre o Pro Archia corresponde à referência Pereira, 1888. A tradução de Xenofonte pode ser encontrada no Brasil com certa facilidade numa edição mais recente: Pereira, 1956.

${ }^{5}$ Pereira, 1854.

${ }^{6}$ Para essa questão terminológica na história da versificação em português, ver Ali, 1999, p. 17-21.
} 
Precedidos de breve prefácio, os versos são apresentados por Pereira em formato bilíngue, com um texto grego transliterado para o nosso alfabeto. O sistema de transliteração utilizado por ele é bastante comum, exceto talvez pela total ausência de diacríticos para representar os acentos gregos e pela prática de diferenciar as vogais eta e ômega de seus pares breves e fechados épsilon e ômicron transcrevendo aquelas como é e ó. Do ponto de vista dos estudos de grego atuais, talvez seja um pouco difícil entender por que Pereira imprime esse texto transliterado, principalmente sem acompanhá-lo dos versos no alfabeto grego, mas é muito provável que as circunstâncias da publicação fossem limitadas em termos tipográficos (uma realidade que não é estranha aos helenistas brasileiros, que, antes do advento dos arquivos PDF e das fontes Unicode, frequentemente tinham que se deparar com livros e artigos com erros crassos na impressão do grego). Excluindo-se alguns casos que parecem ser equívocos do tradutor português ou erros de impressão, nota-se também uma série de outras diferenças nas lições do texto grego quando o comparamos à prática dominante nos editores mais recentes.

Comparando-se o texto de Pereira às edições de West, 1978, e Solmsen, 1990 - as quais podemos considerar representantes de uma espécie de texto standard contemporâneo — ${ }^{7}$ podem-se notar lições diferentes em aproximadamente 30 passos (diferenças quer em relação a ambas as edições recentes, quer a apenas uma delas), sem contar as diferenças de pontuação, que são muito frequentes. Uma das razões dessas diferenças é o fato de que o livro de Pereira não pôde incorporar, é claro, conjecturas de filólogos modernos posteriores ao trabalho do português. Também há casos, contudo, de conjecturas mais antigas que foram deliberadamente ignoradas por Pereira ou publicadas em livros a que ele não teve acesso. Por não incorporar conjecturas que estão muito disseminadas nas edições que circulam hoje, Pereira apresenta um texto que, em muitas passagens, está mais próximo da tradição manuscrita. Um segundo grupo de variantes presentes no texto de Pereira corresponde a escolhas distintas daquelas de West e/ou Solmsen diante de diferentes opções atestadas em manuscritos. Como as opções de West e/ou Solmsen nesse campo também acabaram por se impor na maioria das edições contemporâneas, temos aí mais um fator que dá ao texto grego do livro de Pereira um aspecto bastante distinto. Comparando-o com edições importantes do século XIX (Lanzi, 1808, Goettling, 1843, e Paley, 1883

${ }^{7}$ Cujas características básicas remontam ao trabalho de recensão de Aloisius Rzach (ver esp. Rzach 1913). 
[1. ed. 1861]), com uma edição representativa do século XVI (publicada em Basel, provavelmente em 1544) ${ }^{8}$ e com dois manuscritos do século XV (Arundel MS 522 e Harley MS 6323, ambos da British Library), podemos perceber várias similaridades, algumas das quais terei a oportunidade de comentar mais adiante.

Um exemplo do primeiro caso, aquele concernente a conjecturas

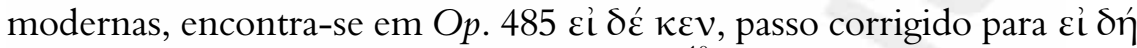
$\kappa^{\prime}$ por Wilamowitz em sua edição de $1928 .{ }^{10} \mathrm{Já}$ em Op. 468 ö@ $\rceil \eta \kappa \alpha$, o texto que hoje é dominante, ő@ $\tau \eta \kappa \iota$, com o dativo em vez do acusativo, remonta a uma correção do século XVIII proposta por Brunck, ${ }^{11}$ mas ignorada por Pereira. Quanto a passagens em que há divergências na própria tradição manuscrita, destaquemos o caso de Op. $394 \mu \varepsilon \tau \alpha \xi \hat{v}$ (que se encontra nos mss. $\mathrm{CDEH}^{12}$ e nos escólios a Hesíodo), que as edições de hoje invariavelmente corrigem para $\mu \varepsilon ́ \tau \alpha \zeta \varepsilon$, uma lição que se encontra apenas em Herodiano (Grammatici Graeci 3.1, 499, 9), num escólio a

${ }^{8}$ Cf. Boccardo e Ramus, 1544. Publicaram-se diversas edições de Hesíodo em Basel no séc. XVI (ver Bennet, 1932, p. 176), uma das quais (provavelmente de 1564) tem um exemplar na Biblioteca Nacional, no Rio de Janeiro. Também a Biblioteca Nacional de Portugal tem um exemplar de uma dessas edições, cuja data estimada é 1542.

${ }^{9}$ Embora o cotejo com essas edições e manuscritos não seja suficiente, é claro, para determinar com exatidão as origens, as datas e os caminhos percorridos pelas variantes apresentadas por Pereira, essas fontes documentam o pertencimento do texto grego de Pereira a uma outra época da transmissão e interpretação da obra hesiódica. Meus comentários não pretendem abordar todas essas variantes, mesmo porque várias delas não produzem diferenças de sentido ou mudanças gramaticais interessantes. Portanto, para não sobrecarregar o leitor com muitas notas, chamo a atenção apenas para algumas lições, que serão suficientes para exemplificar o quão distante é o texto de Pereira em relação à prática de hoje.

${ }^{10}$ Wilamowitz, 1928, ad loc.: Die Anwendung der vorhergehenden allgemeinen Äußerung

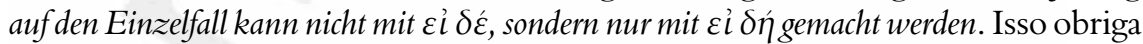
Wilamowitz a mudar $\kappa \varepsilon v$ para $\kappa$ ', para não gerar uma sequência impossível no hexâmetro datílico (uma breve entre duas longas). A lição do filólogo alemão é acolhida por Solmsen, 1990, e é reproduzida em várias edições de hoje, como

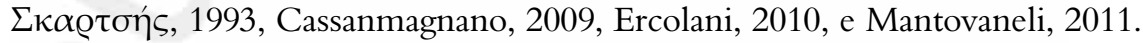

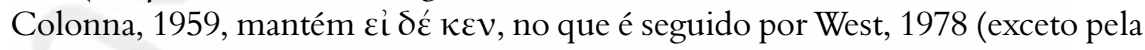
acentuação).

${ }^{11}$ Brunck, 1784, p. 330. A conjectura de Brunck foi posteriormente encontrada por West, 1978, num manuscrito do séc. XIV, identificado em sua edição pela sigla $\psi$.

${ }^{12}$ Siglas de Solmsen, 1990. 
Dionísio Trácio (como uaria lectio) e num escólio à Ilíada (3.29b). ${ }^{13}$ Notase que aqui o texto impresso por Pereira segue a tendência dominante da tradição, ignorando (deliberadamente ou não) os testimonia (que fazem parte da tradição indireta). Por outro lado, Pereira também apresenta variantes atestadas em manuscritos mas não registradas no aparato crítico de nenhuma das edições críticas recentes que consultei. ${ }^{14} \mathrm{Um}$ exemplo

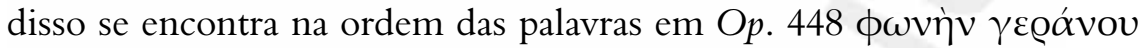

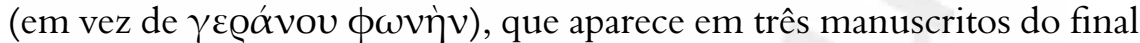
do séc. XV referidos na antiga edição de Paley ${ }^{15}$ (aos quais ele atribui as siglas EFK). Segundo Goettling, 1843, ad loc., a lição aparece em "poucos" códices (entre os quais ele cita um manuscrito da Bibliotheca Vadiana de St. Gallen). Esses manuscritos são hoje considerados secundários e muito raramente levados em conta. Pelo teor de seu comentário, nota-se claramente que Goettling associa a variante a um período ultrapassado da história do texto, enquanto Brunck, 1784, p. 330, observa que é a lição da vulgata. Pode-se encontrar a mesma variante na edição de Basel (Boccardo e Ramus, 1544, p. 32) e no manuscrito Harley MS 6323 (último quartel do séc. XV), f. $54 \mathrm{v}^{16}{ }^{16}$ A omissão, por parte das edições críticas de hoje, de uma série de variantes que observarei abaixo, é sobretudo devida ao fato de as recensões de Rzach e seus continuadores terem definido quais manuscritos eram os mais importantes, de forma que, em relação aos manuscritos que não são investidos dessa autoridade, acaba-se aplicando, de certa forma, o lema de Cobet: Comburendi, non conferendi. ${ }^{17}$ Por outro lado, se o objetivo da Crítica Textual vai além de encontrar o texto "genuíno", mas pode também ser o estudo do texto múltiplo que se apresenta na tradição, mesmo em suas manifestações periféricas (como é o caso de Pereira), a perspectiva muda completamente.

Quanto ao prefácio de Pereira, para o helenista de hoje é fácil perceber que certas opiniões ali registradas, as quais Pereira expressa às vezes

\footnotetext{
${ }^{13}$ Como explica West, 1978 , ad loc., $\mu \varepsilon ́ \tau \alpha \zeta \varepsilon$ tem um sentido que se encaixa melhor na passagem, i.e. "depois", enquanto $\mu \varepsilon \tau \alpha \xi u ́$ significa "no intervalo, no meio". Em Boccardo e Ramus, 1544, p. 28, também se imprime $\mu \varepsilon \tau \alpha \xi \hat{v}$.

${ }^{14}$ Além de West, 1978, e Solmsen, 1990, também Rzach, 1913, Wilamowitz, 1928, e Colonna, 1959.

${ }^{15}$ Paley, 1883.

${ }^{16}$ Disponível on-line no website de manuscritos digitalizados da British Library: <http://www.bl.uk/manuscripts/FullDisplay.aspx?ref=Harley_MS_6323> (último acesso em 04/ 05/2014).

${ }^{17}$ Apud Maas, 1958, p. 52.
} 
em tom categórico e/ou cita como pertencentes à maioria dos críticos, têm pouca ou nenhuma guarida na Filologia contemporânea (e.g. o suposto caráter espúrio dos versos 1-10 ou do episódio de Prometeu e Pandora). Sua defesa da originalidade de Virgílio, por outro lado, soa como dos dias de hoje.

Convém agora expor os critérios utilizados nesta reedição do trabalho de Pereira. Dou abaixo uma transcrição do prefácio, da tradução e do texto grego em caracteres romanos, tal como aparece no livro, a que acrescento uma versão nos caracteres gregos que mantém as lições impressas por Pereira. A pontuação, que, como disse acima em relação ao texto grego, é bastante diferente daquela encontrada nas edições de hoje, também tem peculiaridades no prefácio e nos versos portugueses. Procurei mantê-la sem qualquer mudança (exceto nos casos de evidentes erros de impressão). Corrigi os erros do grego quando eles não puderam ser atestados na tradição manuscrita ou nas edições consultadas e provêm, ao que tudo indica, de enganos do próprio Pereira ou de deslizes tipográficos. Não adaptei a ortografia do texto português, corrigindo apenas os lapsos mais evidentes e uniformizando o uso de maiúsculas. ${ }^{18}$ Os colchetes servem para assinalar correções, tanto no texto português quanto no grego em caracteres romanos. Quando necessário, comento algumas dessas correções. Ao contrário do que fiz acima ao comentar as variantes impressas por Pereira, ao transcrever o texto grego mantive a numeração presente no livro: versos 381-490, 555-615, 772-3, 778-80, 784-5, 803-6, 810. Nas edições de hoje, essas passagens correspondem, respectivamente, a 383-492, 557-617, 7745, 780-2, 786-7, 805-8, 812. Portanto, Pereira utiliza um texto grego que, em relação ao texto standard com que estamos acostumados, omite dois versos antes do atual $383 .{ }^{19}$

Passemos então à transcrição do trabalho de Pereira, começando pelo prefácio. Em seguida vem o texto grego, primeiro em caracteres romanos e depois transliterado para o alfabeto grego. Por fim, ofereço a tradução.

\footnotetext{
${ }^{18}$ Quanto ao uso de maiúsculas no início dos versos, procedimento adotado por Pereira (e corrente em sua época, mas hoje em desuso), está mantido no texto em português e no grego em caracteres romanos, mas não no texto no alfabeto grego. Note-se que em Boccardo e Ramus, 1544, não se usam diacríticos com maiúsculas iniciais. Se Pereira usou uma edição como essa, pode estar aí a explicação para deslizes como o do seu verso 394 (Ós em vez de Hós).

${ }^{19} \mathrm{Cf}$. abaixo nota seguinte.
} 


\section{$\star \star \star$}

[Prefácio, p. 3-4 na fonte]

\section{As Obras e os Dias}

É ainda hoje opinião d'alguns criticos e commentadores, que Virgilio, nas Georgicas, não fez mais do que imitar Hesiodo ; que os primeiros versos d'este poema são uma explanação do titulo da obra do poeta grego, Erga kai Hémerai ; que a comparação seria mais completa, se não se tivesse perdido parte da obra d'este poeta ; e que o próprio Virgilio, no verso 176 do segundo canto - Ascraeumque cano romana per oppida carmen - confessa, que imitara Hesiodo.

Esta opinião é de todo ponto inadmisssivel. Para exprimir a grande differença entre as duas obras, primeiro citaremos a indisputavel auctoridade do commentador allemão, Heyne : nihil exilius, jejunius et aridius Hesiodo, nihil copiosius et plenius Virgilio.

Quanto ao carmen ascraeum do verso 176 do segundo canto das Georgicas, não significa, a nosso ver, senão os preceitos da agricultura, postos em verso, alludindo a Hesiodo, natural de Ascra na Beocia, que foi o primeiro, que na Grecia escreveu sobre os trabalhos do campo. Naquelle verso, Virgilio promette cantar sobre o mesmo assumpto, em que já cantara o poeta de Ascra, uns dez seculos antes d'elle.

É verdade, que em Hesiodo se depara com preceitos de agricultura, que já se encôntrão em Hesiodo ; e alguns até literalmente traduzidos, como succede no verso 299 do canto primeiro - Nudus ara, sere nudus que é traducção literal de - Gymnon speirein, gymnon boótein — do verso 389 de Hesiodo. Mas que havia de fazer Virgilio, que escrevia um poema didascalico sobre agricultura, senão reproduzir o que já se sabia da arte de cultivar a terra ? Assim, não só reproduziu alguma doutrina de Hesiodo, mas tãobem d'outros escriptores gregos, Xenophonte, Aristoteles, e de auctores latinos, Catão, Varrão, etc. Mas as Georgicas não são, de certo, um mero resumo da sciencia mais antiga, e muito menos uma imitação do poema - Erga kai Hémerai- de Hesiodo. Virgilio juntou, aos antigos conhecimentos, o fructo de sua práctica e experiencia ; e compoz uma obra, que encerra, não só preceitos sobre o modo de amanhar os campos, mas tãobem muita doutrina de economia rural. As Georgicas são, no dizer de profundos criticos modernos, o mais perfeito poema, que a antiguidade nos legou.

Hesiodo não era um poeta de profissão, como foi Homero, talvez seo contemporaneo ; era antes, como diz um escriptor allemão, Otfried 
Mueller, um bom pae de familia, a quem o coração se confrangia tanto por certos factos, que suas emoções e pensamentos tomavão naturalmente a forma de poesia.

O pae de Hesiodo residia em Cumas, cidade da Asia Menor ; mas correndo-lhe mal os negócios de sua casa, emigrou para Ascra na Beocia, onde se dedicou á agricultura, e por sua morte legou consideraveis riquezas aos seos dous filhos, Hesiodo e Perses. Perses, que era o mais novo, homem prodigo e ocioso, indo dissipando sua fortuna, poz demanda contra Hesiodo e, peitando os juizes com grossas dadivas, o privou da herança, que the coubera. Perses dissipou tãobem os cabedaes assim obtidos. Hesiodo, apezar de defraudado de grande parte da sua fortuna, ficou ainda senhor de avultados haveres, fructo de seo trabalho; e como irmão extremoso, socorria Perses e lhe dava salutares conselhos. Foi este espirito de reconciliação e o desejo de fazer entrar Perses na carreira da honra e do amor do trabalho, que dictou a Hesiodo a feitura de seo poema, As Obras e os Dias - Erga kai Hémerai.

As Obras e os Dias, talvez o unico poema authentico de Hesiodo, são antes um livro de moral e de economia que de agricultura. O poeta não se propoz, de certo, escrever sobre a arte de cultivar os campos. [S]e formula alguns preceitos agricolas, é para illustrar os conselhos, que dá a seo irmão, mostrando-lhe practicamente, como pode sair da vida ociosa e desregrada, que leva.

Vamos ver a que limitadas dimensões fica reduzido este poema, depois de cortado o que é alheio á agricultura.

Todo o poema consta de 826 versos. ${ }^{20}$

Podemos dividi-lo em 5 partes :

1. ${ }^{\mathrm{a}}$ parte : do $1 .^{\circ}$ verso ao $10 .^{\circ}$ Invocação aos deuses. Estes 10 versos são rejeitados, como espurios, por quasi todos os intérpretes de Hesiodo.

2. ${ }^{a}$ parte : do $11 .^{\circ}$ ao $380 .^{\circ}$ Nesta parte, não há senão principios de ethica, e dous episodios : um, o mytho de Prometheo e Pandora, de 47 a 105 ; o outro, as edades do mundo, de 109 a 201. Ambos estes episodios

\footnotetext{
${ }^{20}$ As edições de hoje trazem, no mínimo, 828 versos. Pereira não inclui na conta dois versos anteriores aos trechos que traduz, pois suas passagens se iniciam no verso que, hoje, recebe o número 383, mas é designado por ele como 381. Possivelmente os dois versos deixados de lado seriam os atuais 120 e 169: ambos são até hoje considerados espúrios por muitos especialistas e são justamente os dois versos que geram em Paley, 1883, uma dupla numeração a partir dos pontos em que aparecem. A mesma prática é adotada em Goettling, 1843, e na primeira edição de Paley, publicada em 1861, e pode ter influenciado a escolha de Pereira. Lanzi, 1808, conserva ambas as linhas.
} 
são geralmente reputados apocryphos.

3. ${ }^{a}$ parte : do 381 . $^{\circ}$ ao $615 .^{\circ}$ É nesta parte que Hesiodo falla de agricultura. Ainda assim, os preceitos agricolas são entremeados de maximas de economia doméstica ; e ha um episodio, de 491 a 555, em que se faz a descripção do inverno. Este episodio tãobem não é do nosso poeta, na opinião de abalizados críticos.

4. ${ }^{\mathrm{a}}$ parte : do 616. ${ }^{\circ}$ a[o] $762 .{ }^{\circ}$ Aqui Hesiodo falla da navegação e do commercio maritimo, e diz a seo irmão, que a vida do mar é mais lucrativa que a dos campos.

5. ${ }^{\mathrm{a}}$ parte : do $763 .{ }^{\circ}$ ao $826{ }^{\circ}$ É a parte, que Hesiodo intitula Hémerai (Dias). É uma especie de calendario, relativo, não ás estações do anno, mas aos dias do mez lunar ; por isso pouca importancia podia ter para a agricultura. Neste calendario se considerão os differentes dias, como faustos ou infaustos para certas occupações e certos factos, presidindo a esta apreciação dos dias a mais grosseira superstição d'aquelles tão arredados tempos. Assim, um dado dia era feliz para contrahir o casamento, outro para o nascimento dos filhos, outro para encetar as pipas de vinho[,] etc. Quanto a agricultura, muito pouco se diz. Apenas se lhe referem doze versos, que são, 772, 773, 778, 779, 780, 784, 785, 803 a 806, 810 .

Vemos, pois, que entre os 826 versos da obra de Hesiodo, não ha sobre agricultura, senão 170 versos na 3. . parte e 12 na 4. parte. É d'estes 182 versos, que vamos dar a traducção, aproximando-nos da letra, quanto possivel.

[Texto grego, p. 7, 9, 11, 13 e 15 na fonte]

Pléiadón Atlageneón epitellomenaón, 381

Archesthai amétou arotoio de, dyssomenaón.

$[\text { Hai dé }]^{21}$ toi nyktas te kai émata tessarakonta

Kekryphatai : autis de periplomenou eniautou

Phainontai, ta próta cherassomenoio sidérou[.]

385

Houtos toi pedión peletai nomos, hoi te thalassés

Eggythi naietaós', hoi t' agkea bésséenta

Pontou kymainontos apoprothi piona chóron

Naiósin, gymnon speiren, gymnon de boótein

Gymnon d' amaein, ei ch' hória pant' etheléstha

Erga komizesthai Déméteros : ós toi hekasta

Hóri['] aexétai, mé pós ta metaxy chatizón

Ptóssés allotrious oikous, kai méden anyssés.

$[H]$ ós kai nyn ep' em’ élthes. egó de toi ouk epidósó,

${ }^{21}$ Haidé: sem espaço na fonte; ao que parece, um erro tipográfico. 
Oud' epimetrésó. ergazeu, népie Persé,

Erga, tat' anthrópoisi theoi dietekméranto :

Mé pote syn paidessi gynaiki te thymon acheuón,

Zéteués bioton kata geitonas, hoi d' amelósin.

Dis men gar kai tris tacha teuxeai : én d' [eti lypés],

Chréma men ou préxeis, sy d' etósia poll' agoreuseis.

Achreios d' estai epeón nomos. Alla s' anóga

Phrazesthai chreión te lysin, limou t' aleórén.

Oikon men prótista, gynaika te, boun t' arotéra,

Ktétén ou gametén hétis kai bousi hepoito.

Krémata d' ein oikó pant' armena poiésasthai :

Mé sy men aités allon, ho d' arnétai, sy de téta,

Hé d' hóré parameibétai, minythé de toi ergon.

Méd' anaballesthai [es] t' aurion, [es] t' ennephin. ${ }^{23}$

Ou gar etósioergos anér pimplési kalién.

Oud' anaballomenos : meleté de toi ergon ophellei.

Aiei d' amboliergos anér atési palaiei.

[É] $\operatorname{mos}^{24}$ dé légei menos oxeos éelioio

Kaumatos idalimou, metopórinon ombrésantos

Zénos eristheneos, meta de trepetai broteos chrós

Pollon elaphroteros : (dé gar tote [S] eirios astér

Baion hyper kephalés kéritrepheón anthrópón

Erchetai ématios, pleion de te nyktos epaurei.)

Émos adéktotaté peletai tmétheisa sidéró

Hylé, phylla d' eraze cheei, ptorthoio te légei.

Témos ar' hylotomein memnémenos hórion ergon.

Holmon men tripodén tamnein, hyperon de tripéchyn[,]

Axona th' heptapodén : mala gar ny toi armenon houtó,

Ei de ken oktapodén apo kai sphyran ke tamoio,

Trispithamon d' hapsin tamnein dekadóró hamaxé,

Poll' epi kampyla kala : pherein de gyén, hot' an heurés,

Eis oikon, kat' oros dizémenos, é kat' arouran,

Prininon : hos gar bousin aroun ochyrótatos estin :

Eut' a $[\mathrm{n}]^{25}$ Athénaiés dmóos en elymati péxas

\footnotetext{
${ }^{22}$ Sem espaço entre as palavras na fonte.

${ }^{23} \mathrm{Na}$ fonte, hes.

${ }^{24}$ Falta o diacrítico na fonte.

${ }^{25} \mathrm{Na}$ fonte, an', um erro. Deve-se observar que em Boccardo e Ramus, 1544, p. 32, nesse mesmo verso, a partícula $\alpha$ $v$ aparece impressa com o espírito e o acento grave sobre o v. Semelhante deslocamento dos diacríticos (em relação ao que se imprime

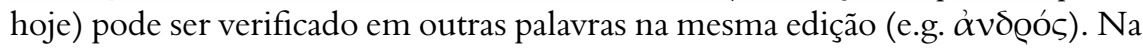
edição de 1564 da Biblioteca Nacional, nota-se inclusive que o espírito e o acento
} 
Gomphoisin pelasas prosaréretai histoboéi

Doia de thesthai arotra ponésamenos kata oikon,

Autogyon kai pékton : epei poly lóion houtó.

Ei ch' heteron g' axais, heteron g' epi bousi baloio.

Daphnés d'é pteleés akiótatoi istoboées.

Dryos elyma, prinou de gyén, boe d' ennaetéró

Arsene kektésthai (tón gar sthenos ouk alapad[n]on) ${ }^{26}$

Hébés metron echonte : tó ergazesthai aristó.

Ouk an tó g' erisantes en aulaki kammem arotron

Axeian, to de ergon etósion authi lipoien.

Tois d' [hama] [tessarakontaetés] ${ }^{27}$ aizéos hepoito,

Arton deipnésas tetratryphon oktablómon,

Hos k' ergou meletón itheian aulak' elaunoi,

Méketi paptainón meth' homélikas, all' epi ergó

Thymon echón : tou d' outi neóteros allos ameinón

Spermata dassasthai, kai episporién aleasthai.

Kouroteros gar anér meth' homélikas eptoiétai.

Phrazesthai d' eut' an phónén geranou epakousés

Hypsothen ek nepheón eniausia kekléguiés,

Hé t' aratoio te séma pherei, kai cheimatos hórén

Deiknyei ombrérou : kradién d' edak' andros abouteó.

Dé tote chortazein helikas boas endon eontas.

Rhéidion gar epos eipein, boe dos kai hamaxan :

Rhéidion d' apanénasthai, para d' erga boessin.

Phési d' anér phrenas aphneios péxasthai hamaxan,

Népios : oude tog' oid' hekaton de te dourath' hamaxés.

Tón prosthen meletén echemen, oikéia thesthai[.]

Eut' an de prótist' arotos thnétoisi phaneié,

Dé tot' ephorméthénai, homós dmóes te kai autos,

Auén kai dierén aroón, arotoio kath' hórén,

Prói mala speudón, hina toi pléthósin arourai.

Eiari polein : thereos de neómené ou s' apatései [:]

Neion de speirein eti kouphizousan arouran.

Neios alexiaré, paidón eukéléteira.

de $\alpha$ $v$ aparecem tão colados e de tal maneira próximos da segunda haste de $v$, que facilmente poderiam ser tomados por um apóstrofo. Se Pereira utilizou uma edição com essas características, pode estar aí a origem do equívoco.

${ }^{26} \mathrm{Na}$ fonte, alapadion, um erro. Curiosamente, no ms. Harley MS 6323, f. 54r, o aparece como correção (escrito sobre outra letra), e em Lanzi, 1808, há um erro tipográfico exatamente nesse ponto: a segunda haste do $v$ não está impressa, dando a impressão de que se trata de um t.

${ }^{27} \mathrm{Na}$ fonte, hamma tessarakonta etés. 
Euchesthai de Dii chthonió, Déméteri th' hagné,

Ektelea brithein Déméteros hieron aktén

Archomenos ta prót' arotou, [hot an] $]^{28}$ akron echetlés

Cheiri labón horpéka boón epi nóton hikéai

Endryon helkontón mesabón : ho de tytthos opisthen

Dmóos echón makelén ponon ornithessi titheié,

Spermata kakkryptón : euthémosyné gar aristé

Thnétois anthrópois : kakothémosyné gar kakisté[.]

[H]óde ken hadrosyné stachyés neuoien eraze,

Ei telos autos opisthen Olympios esthlon opazoi.

Ek d' aggeón elaseias arachnia kai se eolpa

Géthésein, biotoio ereumenon endon eontos.

Euochtheón d' hixeai polion ear : oude pros allous ${ }^{29}$

Augaseai seo d' allos anér kechrémenos estai.

Ei de ken éelioio tropais aroés chthona dian,

[H]émenos améseis, oligon peri cheiros eergón,

Antia desmeuón kekonimenos, ou mala chairón

Oiseis d' en phormó : pauroi de se théésontai.

Allote d' alloios Zénos noos Aigiochoio :

Argaleos d' andressi kata thnétoisi noésai[.]

Ei de ken ops' aroseis, tode ken toi pharmakon eié [:]

Émos kokkyx kokkyzei dryos en petaloisi

To próton, terpei te brotous ep' apeirona gaian,

Témos Zeus hyoi tritó émati, méd' apolégoi,

Mét' ar' hyperballón boos hopl[é]n, mét' apoleipón :

Houtó k' opsarotés pr[ó] téroté isopharizei.

En thymó d' eu panta phyllaseo : méde se 1[é]thoi

Mét' ear ginomenon polion méth' hórios [o]mbros.

(...) Meis gar chalepótatos houtos

Cheimerios, chalepos probatois, chalepos d' anthr[ó]pois[.]

Témos th' hémisy bous', epi d' aneri kai pleon eié

Armaliés [:] makrai gar epirrhotoi euphronai eisi.

Tauta phyllassomenos, tetelesmenon eis eniauton

Isousthai nyktas te kai émata, eisoken authis

Gé pantón métér karpon symmikton ekeiné.

Eut' an d' hexékonta ${ }^{30}$ meta tropas éelioio,

Cheimeri['] ektelesé Zeus émata, dé rha tot' astér

Arktouros prolipón hieron rhoon Ókeanoio,

\footnotetext{
${ }^{28} \mathrm{Na}$ fonte, ho tan. Na edição de Basel, p. 34, aparece ó $\alpha \mathrm{v}$ (como uma só palavra).

${ }^{29}$ Foi eliminada a pontuação (:) presente na fonte no final da linha.

${ }^{30}$ Foi retirada vírgula depois de hexékonta.
} 
Próton pamphainón epitelletai akroknephaios.

Tonde met' orthrogoé Pandionis órto chelidón

Es phaos anthrópois, earos neon istamenoio.

Tén [phthamenos oinas] ${ }^{31}$ peritamnemen : h[ó]s gar ameinon

All' opot' an pher[e]oikos apo chthonos an phyta bainé,

Pléiadas pheugón, tote dé skaphos ouketi oineón.

All' harpas te charassemenai, kai dmóas egeirein,

Pheugein de skierous thókous, kai ep' éó koiton,

Hóré en amétou, hote t'éelios chroa karphé.

Témoutos speudein, kai oikade karpon ageirein,

Orthrou anistamenos, hina toi bios arkios eié.

Éós gar t' ergoio tritén apomeiretai aisan.

Éós toi propherei meu hodou, propherei de kai ergou.

És éte phaneisa poleas epebése keleuthou

Anthrópous, polloisi d' epi zyga bousi tithésin.

Émos de skolymos t' anthei kai écheta tettix

Dendreó ephezomenos ligyrén katacheuet' aoidén

Pyknon hypo pterygón, thereos kamatódeos hóré,

Temos piotatai t' aiges, kai oinos aristos :

Machlotatai de gynaikes, aphaurotatoi de te andres

Eisin, epei kephalén kai gounata Seirios azei,

Aualeos de te chrós hypo kaumatos. alla tot' édé

Eié petraié te skié, kai byblinos oinos,

Maza t' amolgaié, gala t' aigón sbennymenaón,

Kai boos hylophagoio kreas mépó tetokuiés,

Prótogonón t' eriphón. eti d' aithopa pinemen oinon,

En skié [h] ezomenon, kekorémenon [é]tor edódés,

Antion akraeos [Z] ephyrou trepsanta prosópon,

Krénés t' aenaou kai aporrhytou, hé t' atholótos

Tris d' hydatos procheein, to de tetraton hiemen oinou.

Dmósi d' epotrynein Déméteros hieron aktén

Dinemen, eut' an próta phané sthenos Óriónos,

Chóró en euaei kai eutrochaló en alóé.

Metró d' eu komisasthai en aggesin. autar epén dé

Panta bion katathéai eparmenon endothen oikou,

[Théta t'] ${ }^{32}$ aoikon poieisthai, kai ateknon erithon

Dizesthai kelomai, chalepé d' hypoportis erithos,

Kai kyna karch[a]rodonta komein : mé pheideo sitou.

Mé pote s' hémerokoitos anér apo chrémath' helétai.

Chorton d' eskomisai, kai syrpheton, ophra toi eié

${ }^{31} \mathrm{Na}$ fonte, phthamenosoinas.

${ }^{32}$ Thétat' na fonte. 
Bousi kai hémionoisin epéetanon. autar epeita

605

Dmóas anapsyxai phila gounata, kai boe lysai.

Eut' an [d'] Órión kai Seirios es meson elthé

Ouranon, Arktouron d' esidé rhododaktylos Éós,

Ó $[\mathrm{P}]$ ersé, tote pantas apodrepe oikade botrys.

Deixai d' éelió deka t' émata kai deka nyktas.

Pente de syskiasai, hektó d' eis agge' aphyssai

Dora Diónysou polygétheos. Autar epén dé

Pléiades th' Hyades te, to te sthenos Óriónos

Dynósin, tot' epeit' arotou memnémenos einai

Hóraiou : pleión de kata chthonos armenos eié.

Endekaté te, duódekaté te, amphó ge men esthlai.

Hé men ois peikein, hé d' euphrona karpon amasthai.

Menos d' [h]istamenou triskaidekatén aleasthai

Spermatos arxasthai : phyta d' enthrepsasthai aristé.

Hekté d' hé messé mal' asymphoros esti phytoisin.

(...) eriphous tamnein kai [póea] ${ }^{33}$ mélón,

Sékon t' amphibalein poimnéion, épion émar.

Messé d' hebdomaté Déméteros hieron aktén

Eu mal' opipteuonta eutrochaló en alóé

$\mathrm{B}$ [a]llein : hylotomon te tamein thalaméia doura,

Néia le xyla polla, ta t' armena néusi pelontai.

Esthlé men gar t' éde phyteuemen (...)

[Transliteração para o alfabeto grego]

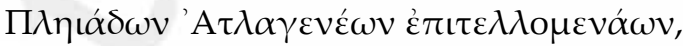

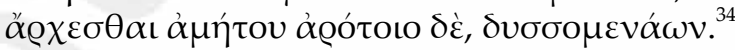

\footnotetext{
${ }^{33} \mathrm{Na}$ fonte, próea.

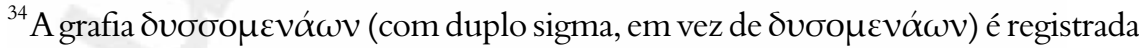
por Paley, 1883 (que a encontra nos 14 manuscritos por ele colacionados, todos códices preservados em bibliotecas inglesas), e Colonna, 1959 (que dá a entender ser essa lição comum a E e H), e aparece no texto grego em Boccardo e Ramus, 1544, p. 28, e Lanzi, 1808, além de se poder verificar no ms. Arundel MS 522, f. 16r (<http://www.bl.uk/manuscripts/FullDisplay.aspx?ref=Arundel_MS_522>, último acesso em 11/ 08/ 2014). Ignorada nos aparatos críticos de Rzach, 1913 ,
} 


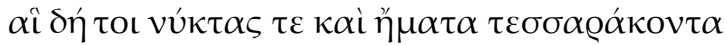

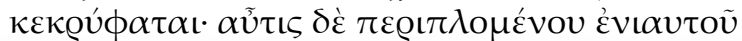

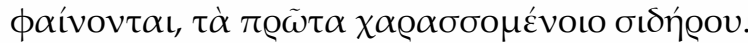

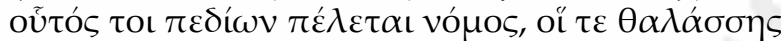

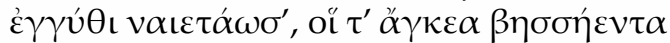

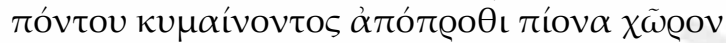

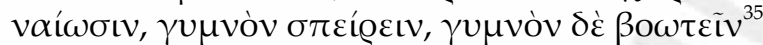

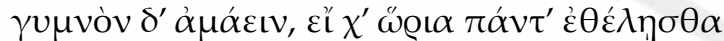
390

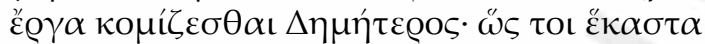

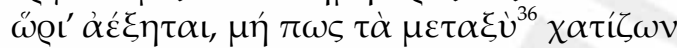

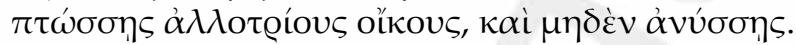

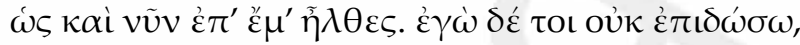

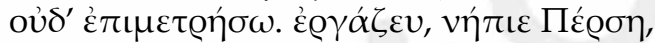

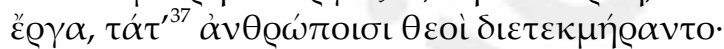

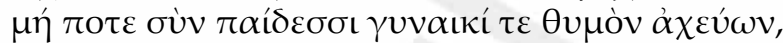

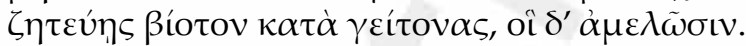

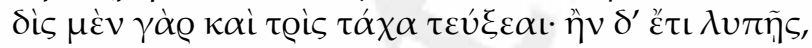

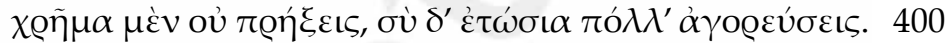

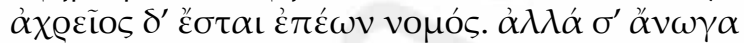

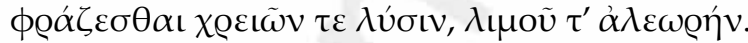

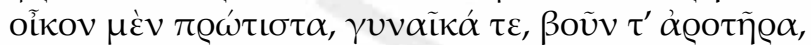

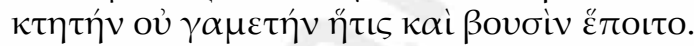

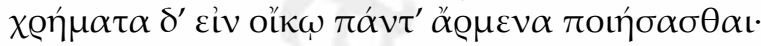
405

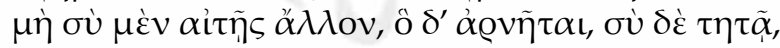

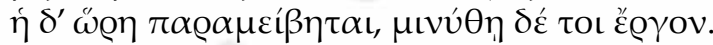

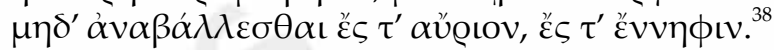

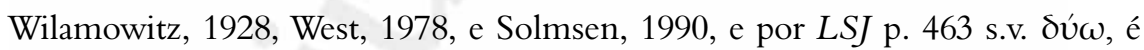
uma grafia hoje obsoleta, talvez devida à necessidade, que teria sido sentida por alguns escribas, de marcar como longa a primeira sílaba desse particípio, já que a quantidade do $v$ varia bastante nas diversas formas do verbo em questão. Brunck, 1784, p. 329, comenta: Perperam vulgo $\sigma$ geminatur.

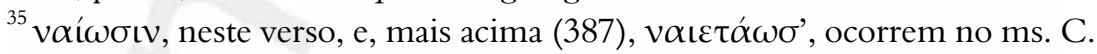

${ }^{36} \mu \varepsilon \tau \alpha \xi \dot{v}$ é a forma que se encontra nos mss. CDEH e também nos escólios. A forma preferida por West, 1978, Solmsen, 1990, e os outros editores mais recentes,

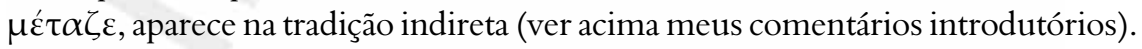
Pereira coincide com Boccardo e Ramus, 1544, p. 28, e Lanzi, 1808.

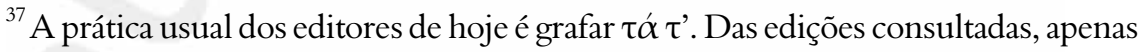
as de Boccardo e Ramus, 1544, p. 28, Goettling, 1843, e Paley, 1883, escrevem as

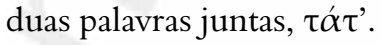

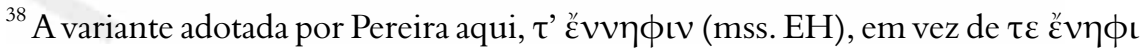
(ms. C), gera um verso espondaico. Também é a lição de Boccardo e Ramus, 1544, p. 30. 


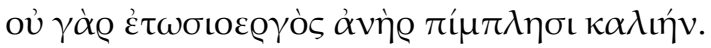

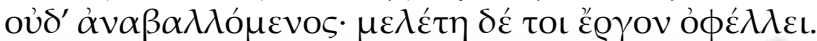

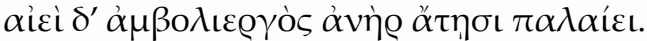

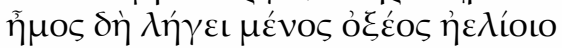

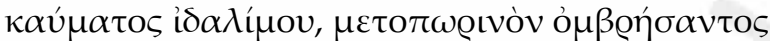

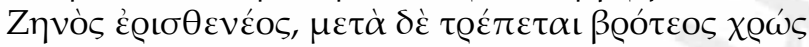

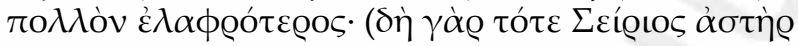

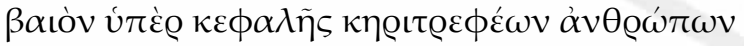

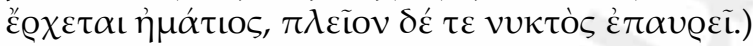

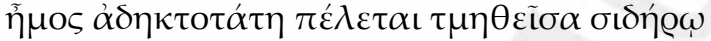

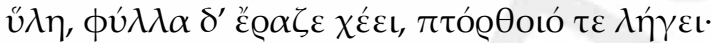

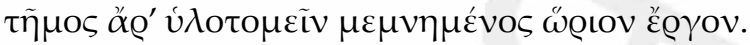

420

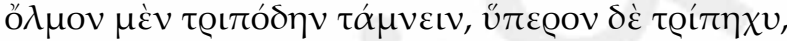

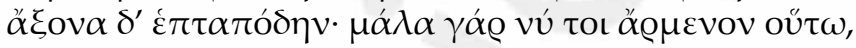

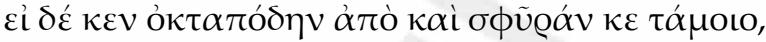

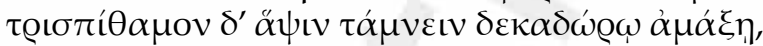

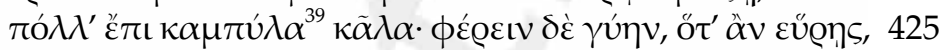

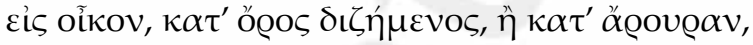

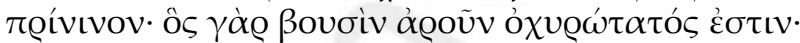

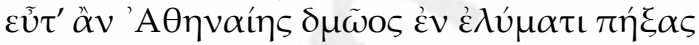

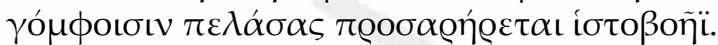

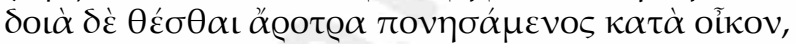

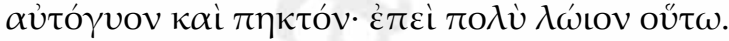

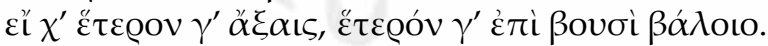

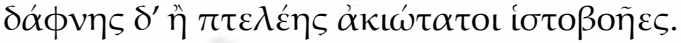

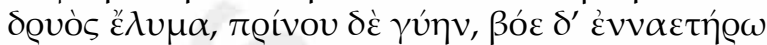

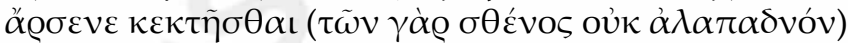

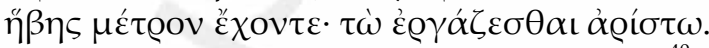

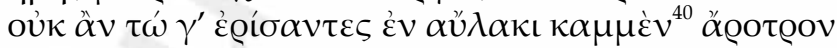

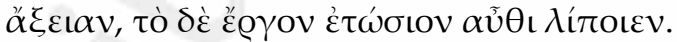

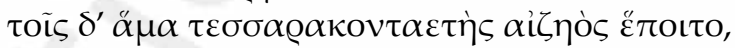

\footnotetext{
${ }^{39}$ West, 1978 (ver comentário ad loc.), e Solmsen, 1990, veem aqui uma só palavra,

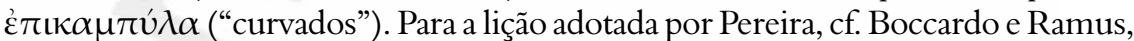
1544, p. 32, Lanzi, 1808, Goettling, 1843, e Paley, 1883.

${ }^{40}$ Todas as edições críticas recentes consultadas escrevem $\kappa \dot{\alpha} \mu \mu \dot{\varepsilon} \nu$, o que corresponde à praxe de hoje em casos como este. $\mathrm{O}$ mesmo ocorre com as edições do séc. XIX que utilizamos, exceto Lanzi, 1808, que traz $\kappa \alpha \mu \mu \dot{v} v$. O ms. Harley MS 6323, que normalmente separa palavras, traz essas duas juntas (f. 54r), assim como a edição de Basel (p. 32). Como se trata aqui de uma assimilação da última

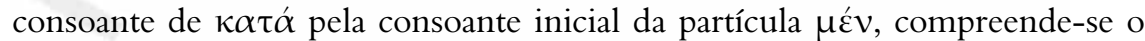
porquê dessa antiga prática de representar assim a junção dos dois itens, por assim dizer, em uma só cadeia fônica.
} 


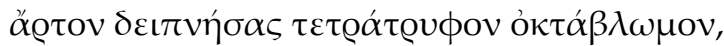
440

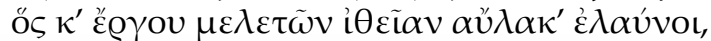

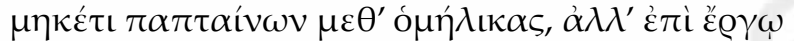

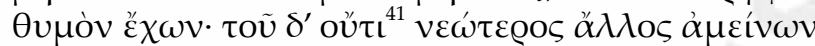

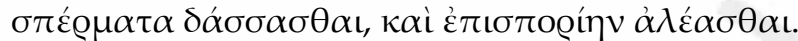

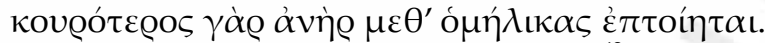

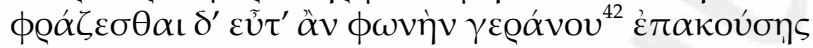

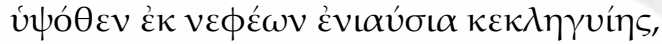

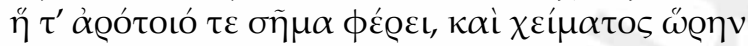

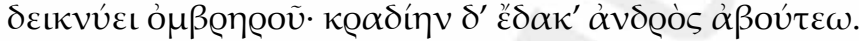

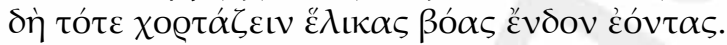

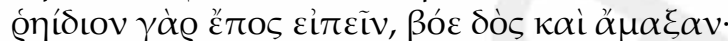

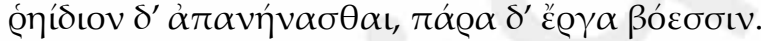

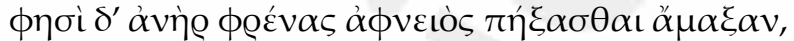

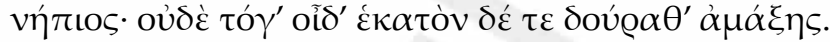

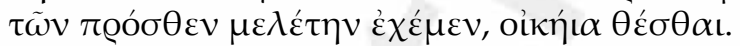

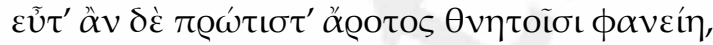

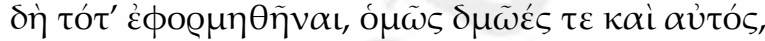

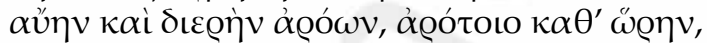

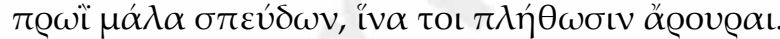

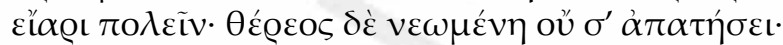

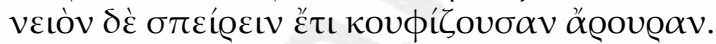

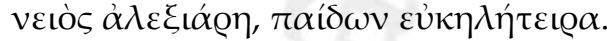

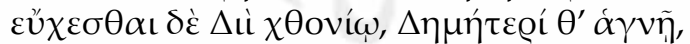

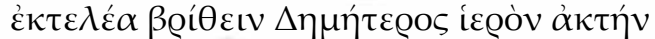

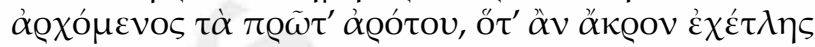

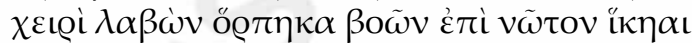

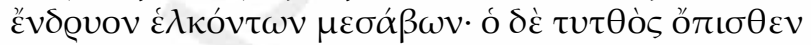

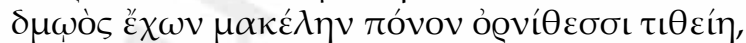

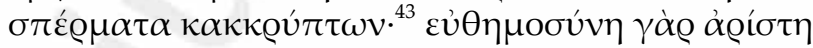

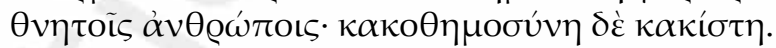

\footnotetext{
${ }^{41}$ oǔt $\tau$, sem espaço, é a convenção nas edições do séc. XIX utilizadas neste trabalho.

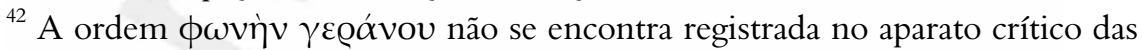
edições de West, 1978, e Solmsen, 1990, mas está atestada em diversas outras fontes (ver acima os comentários introdutórios deste artigo).

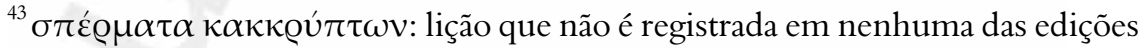
críticas recentes consultadas, é identificada por Lanzi, 1808, p. 289, como lição “da vulgata". Paley, 1883, encontra-a em um manuscrito e na edição Aldina (1495). Goettling, 1843, ad loc., comenta que são [p]auci, neque ii bonae notae os manuscritos que trazem essa variante. Pode-se vê-la em Boccardo e Ramus, 1544, p. 34, e no f. 55v do ms. Harley MS 6323. Já o ms. Arundel MS 522, f. 20r, traz $\sigma \pi \varepsilon ́ \mathrm{Q} \mu \alpha$ $\kappa \alpha \tau \alpha \kappa \varrho u ́ \pi \tau \omega \nu$, a lição hoje dominante.
} 


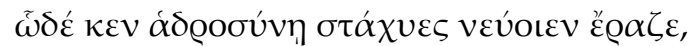

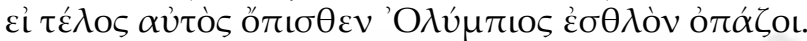

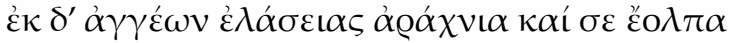

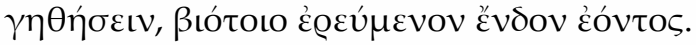

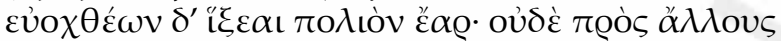

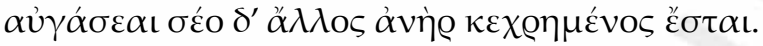

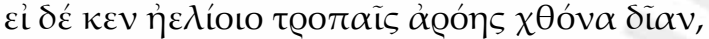

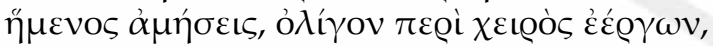

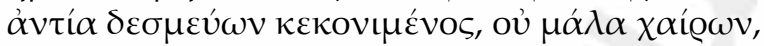

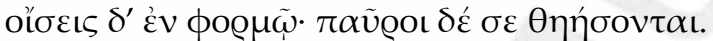

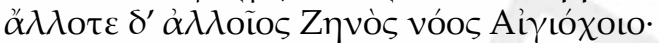

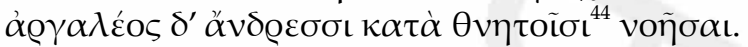

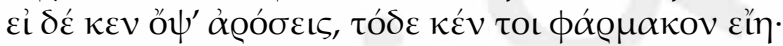

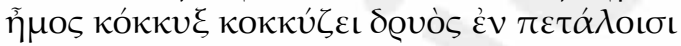

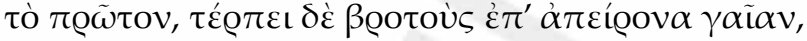

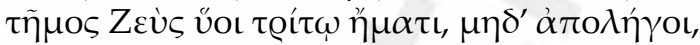

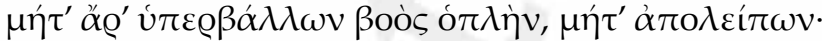

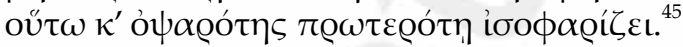

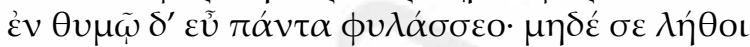

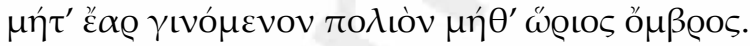

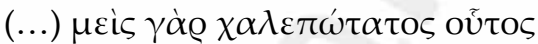

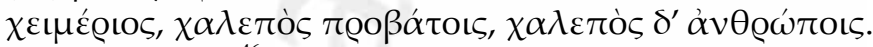

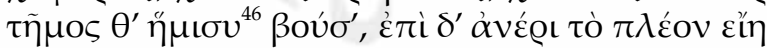

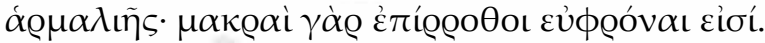

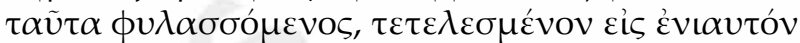

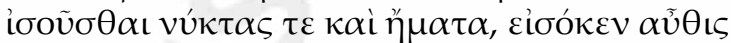

${ }^{44} \kappa \alpha \tau \dot{\alpha} \theta v \eta \tau$ ̃õ $\sigma$ (em vez de $\kappa \alpha \tau \alpha \theta v \eta \tau o \tilde{\sigma}$ ) é lição registrada como da vulgata por Goettling, 1843, ad loc., e é o que imprimem Boccardo e Ramus, 1544, p. 36, Lanzi, 1808, e Paley, 1883. Pode-se verificar a variante no ms. Arundel MS 522, f. $20 \mathrm{v}$. Teríamos de ver aí o verbo $\kappa \alpha \tau \alpha$ voć $\omega$ em tmese.

${ }^{45}$ Embora não seja sequer mencionado pelas edições críticas recentes, o indicativo

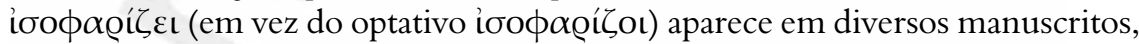
incluindo Harley MS 6323, f. 56r, e é a lição impressa em Boccardo e Ramus, 1544, p. 36. De fato, não se espera ăv, ou seu equivalente homérico $\kappa \dot{\varepsilon}(v)$, com presente do indicativo, mas certos escribas medievais ou editores renascentistas parecem não saber disso. Brunk, 1784, p. 331: Optativum requirit recti scribendi ratio. (...) in impressis, [verbum est modi] indicativi. A tradução de Pereira, "[p]oderá (...) assimilhar-se", cabe para a construção com optativo.

${ }^{46} \theta^{\prime} \eta ๊ \mu t \sigma v$ : lição que, embora não apareça no texto ou no aparato crítico da edições do século XIX e XX consultadas nem nos mss. Harley MS 6323 e Arundel MS 522, é a variante impressa em Boccardo e Ramus, 1544, p. 40. 


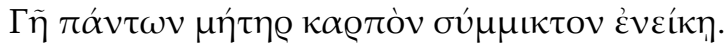

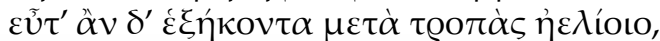

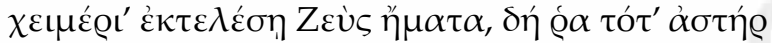

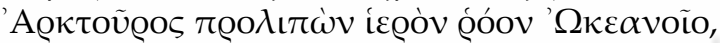

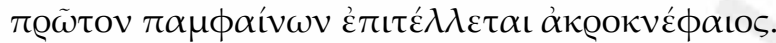

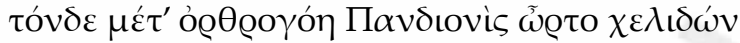

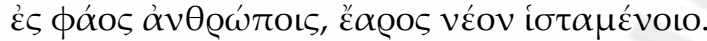

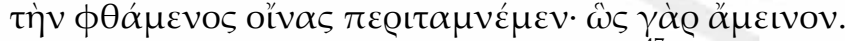

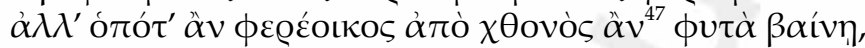

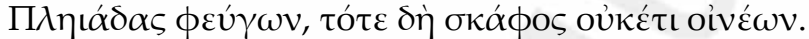

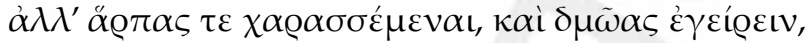

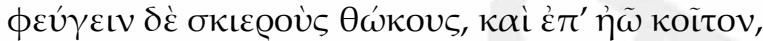

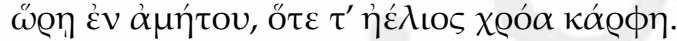

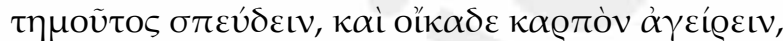

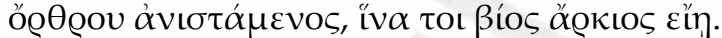

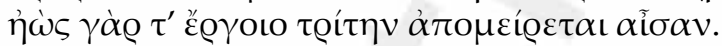

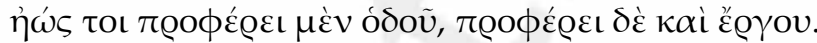

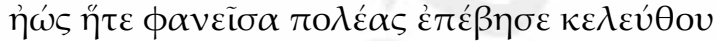

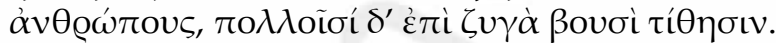

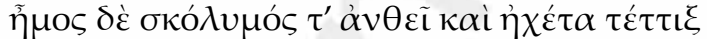
580

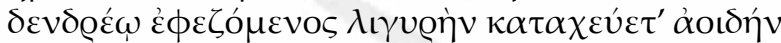

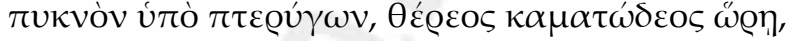

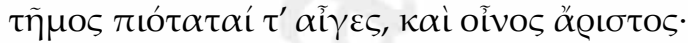

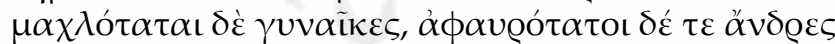

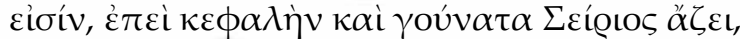

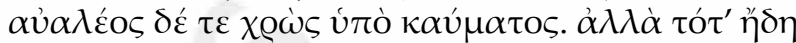

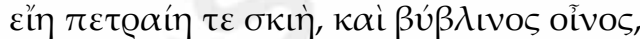
$\mu \tilde{\alpha} \zeta \alpha \tau^{\prime} \dot{\alpha} \mu \mathrm{o} \lambda \gamma \alpha \dot{\eta} \eta, \gamma \alpha \dot{\alpha} \lambda \alpha \tau^{\prime} \alpha \hat{i} \gamma \tilde{\omega} \nu \sigma \beta \varepsilon v \nu v \mu \varepsilon v \alpha \dot{\alpha} \omega v$,

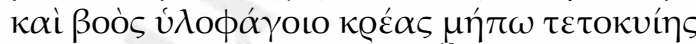

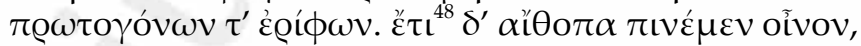
590

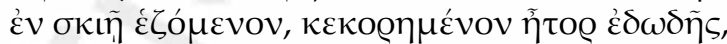

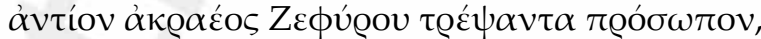

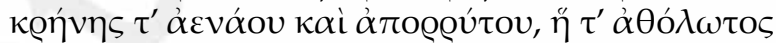

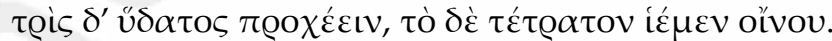

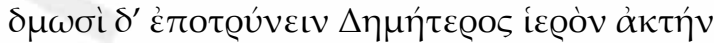

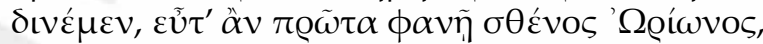

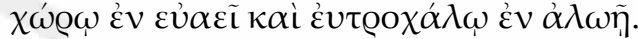

\footnotetext{
${ }^{47}$ àv: ignorada no aparato crítico das edições recentes, essa lição é atribuída a vários manuscritos por Paley, 1883. É a variante adotada em Boccardo e Ramus, 1544, p. 42, e no ms. Arundel MS 522, f. 24v.

${ }^{48}$ Éं $\tau$ (em vez de $\left.\dot{\varepsilon} \pi \mathrm{i}\right)$ : completamente ignorada nas edições críticas recentes e do séc. XIX, a lição aparece em Boccardo e Ramus, 1544, p. 44.
} 


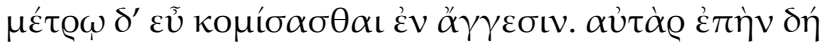

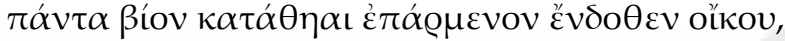

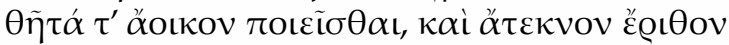
600

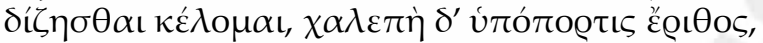

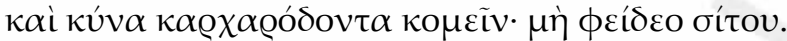

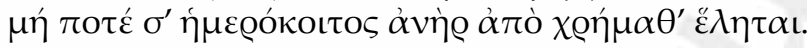

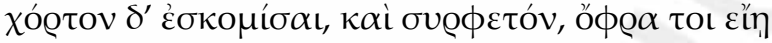

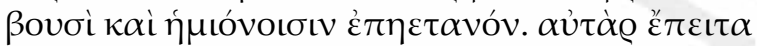

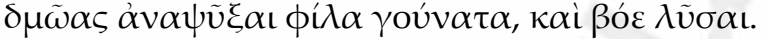

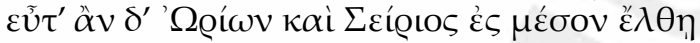

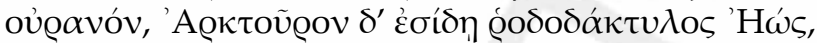

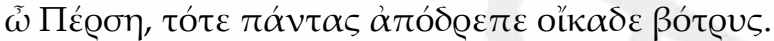

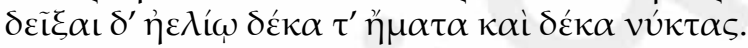

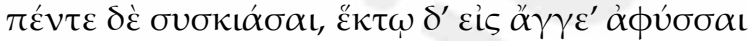

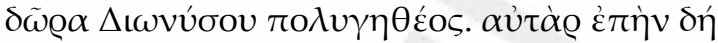

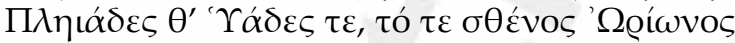

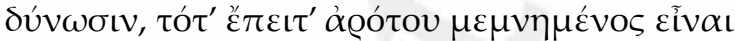

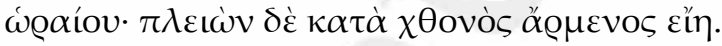

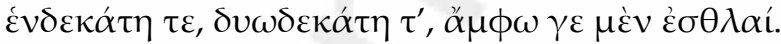

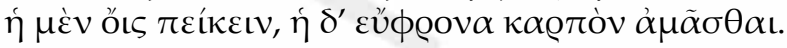

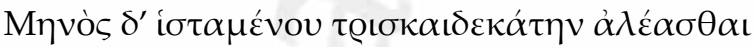

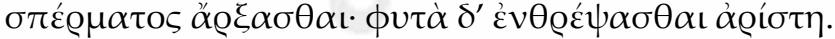

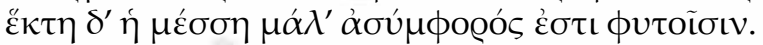

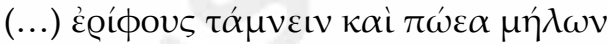

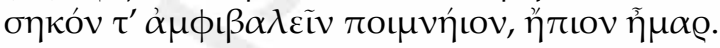

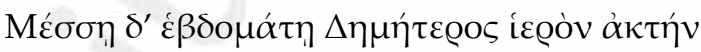
803

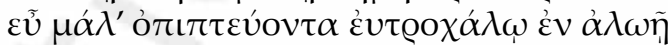

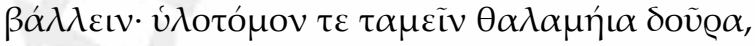

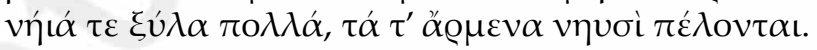

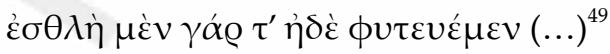

[Tradução, p. 6, 8, 10, 12 e 14 na fonte]

Assim que as Pleiades, de Atlante filhas[,]

\footnotetext{
${ }^{49}$ A seleção de Pereira é aqui muito infeliz, pois omite o sujeito $\pi \varrho \omega \tau i ́ \sigma \tau \eta ~ \delta '$ عivòs (verso anterior).
} 
Nascerem, á colheita dá principio, E lavra, logo que ellas se puzerem. Quarenta dias e quarenta noites Esta constellação está occulta, Mas revolvido o anno, reapparece, Quando se estão as foices afiando.

Tal é a lei dos campos para aquelles, Que perto do agitado mar habitão E p'ra os que vivem nos selvosos valles. Despido lavra e assim semeia e colhe, Se a tempo quer ter os dons de Ceres, E para não andares mendigando, Com inutil trabalho muitas vezes. Assim vieste agora ter comigo :

Mas não te dou mais nada, nem te empresto.

Ó insensato Perses, ao trabalho,

Que os deuses para os homens destinárão, Applica-te : não faças com que tenhas

De ir afflicto buscar á vizinhança

A subsistencia da mulher e filhos,

Sujeitando-te ainda á negativa.

Duas vezes ou tres terás soccorro,

Pode ser ; se a pedir continuares,

Nada conseguirás ; será inutil

Tudo quanto disseres. Recommendo-te,

As dívidas pagar, fugir da fome.

Tu deves possuir, antes de tudo, Casa, mulher e um boi para lavrares ;

Obtem uma mulher, solteira ainda,

Que tracte de teo gado e tenha em ordem

As cousas de tua casa ; não succeda,

Haveres de pedir soccorro alheio,

Sujeitando-te a seres repellido.

Repara tu, que não decorra o tempo,

E o fructo do trabalho diminua.

Para amanhan e p'ra depois não deixes

$\mathrm{O}$ que tens de fazer. $\mathrm{O}$ preguiçoso

O celleiro não enche. A diligencia

Avultará o fructo do trabalho:

Pelo contrario, o homem negligente

Luctando sempre está com prejuizos.

Quando o calor solar, que desafia

O transpirar, a decrescer começa,

E o omnipotente Jupiter no outomno

Chover, e bem mais presto andar o homem 
(Porque, nessa estação, o astro Sirio

Espaço breve está, durante o dia,

Sobre nossas cabeças ; é de noite

Que por mais longo tempo se nos mostra);

Quando a madeira menos se carcome,

Depois de derribada p'lo machado ;

Quando das árvores as folhas caem,

E não se desenvolvem mais os ramos ;

Então é tempo de cortar madeiras.

Fabricarás um gral, cujo diametro

Tenha tres pés e cuja mão tres covados:

Um eixo corta, palmos tendo septe,

Que é muito apropriado comprimento :

Se tiver mais, separa d'elle um masso.

Prepara numerosas peças curvas

E pinas de tres palmos para rodas

De carros de dez palmos de comprido.

Procura na montanha ou na planicie

Um apo de azinheiro ; e se o encontrares,

Transporta-o, sem detença, para casa.

É madeira mui rija para o arado.

Ao apo o artifice com pregos junte

O dental e o temão. Porêm tu deves

Ter dous arados ; um, que o apo tenha

E o temão d'uma peça unicamente ;

Outro, em que as duas partes se distingão.

Em teres dous arados ha proveito.

Se um d'elles quebra, junge os bois ao outro.

O temão de loureiro ou de olmo seja.

De carvalho o dental, de azinho o apo.

D'uma junta de bois de nove annos

Precisas (seo vigor existe ainda) :

Em meia edade estão ; para o trabalho

Muito melhores são. Elles não brigão,

Os arados não quebrão, e d'est'arte

Nunca os serviços incompletos ficão.

Homens de annos quarenta os bois conduzão,

Depois de quadrifido pão comerem,

Em oito partes dividido sendo.

Assim ao seo trabalho entregues todos,

Os regos abrirão em linha recta

E não distrahirão os companheiros.

Outro mais novo não seria idoneo

Para a semente derramar no campo,

Para evitar segunda sementeira. 
Com seos coetaneos os mancebos folgão.

Quando nas altas nuvens tu ouvires

A annual voz do grou, que prenuncia

A chegada do inverno e o tempo proprio

Para lavrar, e o coração afflige

D'aquelle agricultor, que bois não tenha,

Então em teos curraes os bois sustenta.

Tão facil é dizer [:] «Ó meo amigo,

Tua junta de bois e um carro empresta-me» :

Como dizer o amigo, recusando-se :

«Os bois lavrando estão minha fazenda».

Jactancioso então deseja um carro

Construir ; porêm louco desconhece,

Que de cem peças todo o carro consta.

Convem cuidar a tempo nestas cousas.

Chegado sendo o ensejo de lavrares,

Trabalha tu e os teos, saindo cedo,

Humida ou sêcca embora esteja a terra,

P'ra que teos campos deem pingues messes.

Na primavera volta para cima

O solo, que volvido novamente

De verão, não illude as esperanças.

Semeia, em quanto leve, teo pousio,

Que evita maldicções e alegra os filhos.

Quando tu a lavrar principiares,

E uma das mãos tiveres na rabiça,

Emquanto a outra vae tocando o dorso

De teos bois, que se jungem por correias

Á canga, que ao temão cavilha prende ;

Pede a Jove infernal e á casta Ceres,

Que de Ceres os sacros dons progridão.

Atraz um homem vá com uma enchada

A semente cobrindo, e d'este modo

As aves molestando. As boas praxes

Optimas são para os mortaes, e mostra

O desarranjo pessimos effeitos.

Penderão para terra com o pêso

As espigas, se Júpiter permitte.

Das arcas tira as teias das aranhas,

Por quanto espero, que terás o gosto

De desfructar o que puzeres dentro.

Bem fornecido chegarás alegre

Á branca primavera, sem te veres

Forçado a olhar os outros ; ao contrário

Terão de precisar de ti os outros. 
Mas se lavrasses a divina terra

No tempo do solsticio, estar podias

Sentado, o que viesse a mão colhendo.

Que mui pouco seria, e de poeira

Coberto, e sem prazer terias molhos

De atar e em um cabaz mettel-os todos.

Poucos serão os que p'ra ti olharem.

De Jupiter Egiocho varia

O designio, aos mortaes difficil sempre

De perceber. Porêm se tu lavrares,

Sendo já tarde, os unicos remedios

Serão tres dias de continua chuva,

Que as pegadas dos bois de todo enchão,

Quando o cantar do cuco principia

Sobre a folhagem do carvalho e causa

Prazer aos homens na espaçosa terra.

Só assim poderá quem lavra tarde

Assimilhar-se ao que mais cedo lavra.

Portanto sempre deves ter presente,

Quando a flor alvejar a primavera,

E quando a chuva seja favoravel.

Perigo tem aquelle mez de inverno,

E muito para o gado e para os homens.

Põe a meia ração bovino gado,

Porêm mais alimento o homem tenha.

As longas noites bom succorro prestão.

Esta regra seguindo, proporciona

Á grandeza dos dias e das noites

As rações de teos bois, até que o anno

Acabe, e então a terra, mãe de todos,

De novo fructos varios patenteie.

Quando Jove perfaz sessenta dias

Após hiemal solsticio, a estrella Arcturo,

Deixado o sacrosancto curso tendo

Do oceano, apparece radiosa,

Pela primeira vez, ao fim da tarde.

Costuma levantar-se depois d'ella

A filha de Pandíon, a andorinha,

Que de manhan exprime seos queixumes,

Quando já vem chegando a primavera.

Para podar as vides, eis o tempo.

Quando, porêm, o caracol ascende

Para as plantas, das Pleiades fugindo,

Não é já tempo de cavar as vinhas. 
Afia então a foice, activa os servos.

No tempo da colheita, quando o astro

Do dia cresta a pelle, tu evita

A fresca sombra e da manhan o somno.

Então apressa-te, a colheita faze

E para casa os cereaes conduze,

Levantando-te cedo, a fim de teres

Em abundancia as cousas necessarias.

A madrugada obtem a terça parte

Do trabalho total de cada dia,

A madrugada, que assomado tendo

Aos bois o jugo põe, e muitos homens

De casa faz sair, os apressura

Em seo caminho e activa no trabalho.

Assim que tenhão flor as alcachofras

E a sonora cigarra, muitas vezes,

Pousada sobre as árvores, entoe,

Com suas azas, trémulas cantigas,

Pela estação do trabalhoso estio,

Então as cabras tornão-se mui gordas,

O vinho é optimo, as mulheres mostrão

Muita lascivia, os homens são muito fracos,

Porque Sirio os joelhos e a cabeça

Cresta, com o calor o corpo secca.

Á sombra d'uma gruta saboreia

Biblino vinho, de pastor os bolos,

Leite de cabra não amamentando,

Carne de vacca ainda não parida,

Alimentada sendo na floresta,

E tãobem a de tenros cabritinhos.

Depois de satisfeito de comeres,

Sentado á sombra, aos [Z] ephyros fagueiros

Voltando o rosto, bebe vinho tinto

Com agua pura, que da fonte corra.

Tres partes sejão de agua, uma de vinho.

Quando Orionte apparecido tenha,

A teos servos ordena, que debulhem

Os sacros dons de Ceres, em logares

Muito bem aplanados e ventosos :

Mede e recolhe o grão em boas arcas.

Quando a final a novidade tenhas

Dentro de casa, accommodada toda,

Recommendo, que tomes um creado,

Sem familia, e uma serva, sem ter filhos.

Serva com filhos é nociva sempre. 
Convem haver um cão de agudos dentes,

Ao qual não regateies o alimento,

Para que os homens, que de dia dormem,

Não venhão subtrahir os teos haveres.

Egualmente recolhe o feno e a palha

Para o penso annual dos bois e mulos.

Depois d'isto, teos servos recuperem

Suas fôrças, e tira aos bois o jugo.

Quando Orionte e Sirio tem chegado

A meio ceo, e a Aurora vê Arcturo,

Então, ó Perses, colhe e para casa

Trata de conduzir as uvas todas.

Espaço de dez dias e dez noites,

Ao sol expostas deves conserval-as,

Cinco dias á sombra, e ao sexto lança

Em vasilhas os dons do alegre Baccho.

Quando porêm as Pleiades se ponhão,

As Hyades e o válido Orionte,

De lavrar é então chegado o tempo.

Oxalá o anno próspero te corra.

Os dias onze e doze são proficuos,

Um para tosquiares as ovelhas,

Outro para colheres as searas.

No decimo terceiro, não semeies ;

Mas o plantar convem-te certamente.

O dia dezaseis nocivo ás plantas

Se considera. (...)

Sexto é bom p'ra cabritos e cordeiros

Castrar, e armar redis para o rebanho.

Cuidado tem, no dia desasete,

De deitar, numa eira muita lisa,

Os dons de Ceres : cortem-se madeiras

Para edificação de náos e casas.

Nono para plantar se ostenta proprio. 


\section{Referências}

ALI, M. S. Versificação portuguesa. São Paulo: Edusp, 1999.

ARUNDEL MS 522. London: British Library, Digitised manuscripts, <http:// www.bl.uk/manuscripts/FullDisplay.aspx?ref=Arundel_MS_522> (último acesso em 11/ 08/ 2014).

BENNET, J. W. Spenser's Hesiod. American Journal of Philology, Baltimore, vol. 52, n. 3, p. 176-81, 1931.

BOCCARDO, G. F.; RAMUS, I. Hesiodi Ascrei opera. Basel: I. Oporinus, 1544.

BRUNCK, R. F. P. 'HӨıкウ̀ тоínбıs sive Gnomici poetae Graeci. Straßburg: Bibliopolium Academicum, 1784.

CASSANMAGNANO, C. Esiodo, Tutte le opere e $i$ frammenti con la prima traduzione degli scolii. Milano: Bompiani, 2009.

COLECÇÃO PEREIRA, JOÃO FÉLIX. Lisboa: Biblioteca Nacional de Portugal, Colecções, <http://acpc.bn.pt/colecoes_autores/n32_pereira_joao_felix.html> (último acesso em 02/ 05/2014).

COLONNA, A. Hesiodi Opera et dies. Milano/Varese: Istituto Editoriale Cisalpino, 1959.

ENCYCLOPEDIA E DICCIONARIO INTERNACIONAL. Organizado e redigido com a colaboração de distinctos homens de sciencia e lettras. Rio de Janeiro/ Nova York: W. M. Jackson, s.d. (vol. XV, p. 8693, s.v. Pereira, João Felix). ERCOLANI, A. Esiodo, Opere e giorni: introduzione, traduzione e commento. Roma: Carocci, 2010.

GOETTLING, K. Hesiodi carmina. 2. ed. Coburg/ London: D. Nutt, 1843.

GRANDE ENCICLOPÉDIA PORTUGUESA E BRASILEIRA. Lisboa/ Rio de Janeiro: Editorial Enciclopédia, s.d. (vol. XXI, p. 148-9, s.v. João Félix).

HARLEY MS 6323. London: British Library, Digitised manuscripts, <http:// www.bl.uk/manuscripts/FullDisplay.aspx?ref=Harley_MS_6323 > (último acesso em 04/ 05/ 2014).

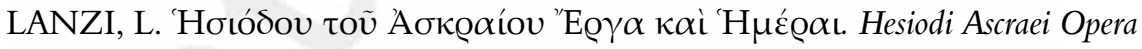
et dies. Di Esiodo Ascreo I Lavori e le giornate. Firenze: Carli e C'., 1808.

MAAS, P. Textual criticism. Trad. B. Flower. Oxford: Clarendon Press, 1958.

MANTOVANELI, L. O. Os trabalhos e os dias, Hesíodo. São Paulo: Odysseus, 2011.

PALEY, F. A. The epics of Hesiod. 2. ed. rev. London: Whitaker and Co./ George Bell and Sons, 1883 (1. ed. 1861).

PEREIRA, J. F. Abridgement of the history of Portugal. Rev. A. V. Meirelles. Lisboa: A. Martins, 1854.

PEREIRA, J. F. As obras e os dias: traducção do original grego em verso endecasylabo. Apreciação d'este poema de Hesiodo, como livro de agricultura, com a traducção dos versos, que se referem a esta sciencia, por João Felix Pereira, agronomo. Lisboa: Typographia do jornal — O Paiz, 1876. 
PEREIRA, J. F. Texto, tradução e analyse da oração de Cicero Pro Archia poeta. Lisboa: Imprensa de Lucas Evangelista Torres, 1888.

PEREIRA, J. F. Xenofonte, Ciropedia. Rio de Janeiro: W. M. Jackson, 1956.

PINHEIRO, A. E.; FERREIRA, J. R. Hesíodo, Teogonia; Trabalhos e dias. Lisboa: Imprensa Nacional-Casa da Moeda, 2005.

ROLIM DE MOURA, A. Hesíodo, Os trabalhos e os dias. Edição, tradução, introdução e notas. Curitiba: Segesta, 2012.

RZACH, A. Hesiodus, Carmina. 3. ed. Leipzig: Teubner, 1913.

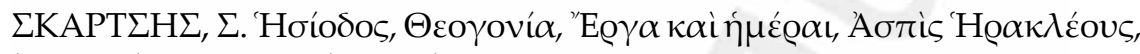

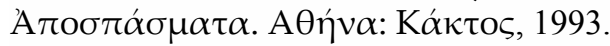

SOLMSEN, F.; MERKELBACH, R.; WEST, M. L. Hesiodi Theogonia, Opera et dies, Scutum, Fragmenta Selecta. 3. ed. Oxford: Oxford University Press, 1990.

VON WILAMOWITZ-MOELLENDORFF, U. Hesiodos, Erga. Berlin: Weidmann, 1928.

WERNER, C. Hesíodo, Trabalhos e dias. São Paulo: Hedra, 2013.

WEST, M. L. Hesiod, Works \& Days. Oxford: Oxford University Press, 1978. 